\title{
E-cigarette use is differentially related to smoking onset among lower risk adolescents
}

\author{
Thomas A Wills, ${ }^{1}$ James D Sargent, ${ }^{2}$ Frederick X Gibbons, ${ }^{3}$ Ian Pagano, ${ }^{1}$ \\ Rebecca Schweitzer ${ }^{4}$
}

- Additional material is published online only. To view please visit the journal online (http://dx.doi.org/10.1136/ tobaccocontrol-2016-053116)

${ }^{1}$ University of Hawaii, Cancer Center, Honolulu, Hawaii, USA ${ }^{2}$ Geisel School of Medicine at Dartmouth, Lebanon, New Hampshire, USA

${ }^{3}$ Center for Health, Intervention \& Prevention, University of Connecticut, Storrs, Connecticut, USA

${ }^{4}$ Office of Public Health Studies, University of Hawaii at Manoa, Honolulu, Hawaii, USA

\section{Correspondence to}

Dr Thomas A Wills, Epidemiology Program, University of Hawaii Cancer Center, 701 llalo Street, 5th floor, Honolulu, HI 96813, USA; twills@cc.hawaii.edu

Received 11 April 2016 Revised 18 July 2016 Accepted 2 August 2016 Published Online First 19 August 2016

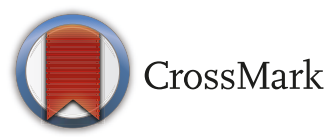

To cite: Wills TA, Sargent JD, Gibbons FX, et al. Tob Control 2017:26:534-539.

\section{ABSTRACT}

Objective E-cigarette use has been linked to onset of cigarette smoking among adolescents, but some commentators have suggested that this simply reflects high-risk adolescents being more likely to use e-cigarettes and to smoke. We tested whether the effect of e-cigarette use for smoking onset differs for youth who are lower versus higher on propensity to smoke. Methods School-based survey with a longitudinal sample of 1136 students (9th-11th graders, mean age 14.7 years) in Hawaii, initially surveyed in 2013 (T1) and followed up 1 year later (T2). We assessed e-cigarette use, propensity to smoke based on 3 psychosocial factors known to predict smoking (rebelliousness, parental support and willingness to smoke), and cigarette smoking status. Analyses based on T1 neversmokers tested the relation of $\mathrm{T} 1$ e-cigarette use to $\mathrm{T} 2$ smoking status for participants lower versus higher on T1 propensity to smoke.

Results The relation between $\mathrm{T} 1$ e-cigarette use and T2 smoking onset was stronger among participants with lower levels of rebelliousness and willingness and higher levels of parental support. A multiple logistic regression analysis with $\mathrm{T} 2$ smoking as the criterion tested the cross-product of $\mathrm{T} 1$ e-cigarette use and $\mathrm{T} 1$ smoking propensity score; the interaction $(\mathrm{OR}=0.88, \mathrm{p}=0.01$ ) indicated a significantly larger effect for smoking onset among lower risk youth.

Conclusions The results indicate e-cigarette use is a risk factor for smoking onset, not just a marker of high risk for smoking. This study provides evidence that ecigarettes are recruiting lower risk adolescents to smoking, which has public health implications.

\section{BACKGROUND}

During the past 5 years, there has been a dramatic increase in the prevalence of e-cigarette use among adolescents in the USA $^{1}$ and other countries. ${ }^{2}$ Moreover, a substantial proportion of adolescents who use e-cigarettes also smoke combustible cigarettes (ie, dual users). ${ }^{3-5}$ A concern has been raised among public health researchers about whether ecigarette use will result in an attitudinal renormalisation of smoking, ${ }^{6}$ but it has been unclear whether dual use simply reflects an association of patterns or whether e-cigarette use may be linked to uptake of smoking. ${ }^{2} 7$

Studies of adolescents and young adults have indicated that persons who use e-cigarettes have more favourable attitudes about smoking combustible cigarettes. ${ }^{8-10}$ In addition, several studies have shown that adolescents who use e-cigarettes only are intermediate in risk status between total non-users and dual users. This suggests that e-cigarettes are operating to recruit lower risk adolescents to substance use. ${ }^{5} 1112$ However, these studies were cross-sectional and did not provide information about temporal relationships.

Additional evidence on this question has come from recent longitudinal studies, which show that among samples of never-smokers, youth who use e-cigarettes are more likely to start smoking combustible cigarettes 6 months to 1 year later. ${ }^{13-16}$ The analyses of the longitudinal data included multiple covariates and demonstrated that the effect of e-cigarettes for smoking onset was not attributable to a range of other variables.

However, critics of e-cigarette research have suggested that these results merely reflect a phenomenon in which adolescents who use e-cigarettes are those who were going to smoke anyway. In this view, e-cigarette use was simply a reflection of highrisk status and had little to do with the onset of smoking. ${ }^{17} 18$ Although this formulation ignores important methodological characteristics of the studies, it does produce a testable proposition: e-cigarette use will be related to smoking onset primarily among those adolescents who were at high risk for smoking to begin with.

We examined this proposition with data from a sample of adolescents surveyed on two occasions over a 1-year period. We determined a propensity score that was empirically related to smoking onset and tested whether the relation between initial ecigarette use and onset of smoking differed as a function of initial propensity to smoke. The propensity score was based on prior research indicating smoking onset prospectively linked to high rebelliousness, low parental support and some level of willingness to smoke. ${ }^{19-21}$

\section{METHODS}

\section{Participants and procedure}

The participants were students in six high schools (four public and two private) on Oahu, Hawaii. The schools were selected to be representative of school systems in Hawaii. The sample is the same as in a previous report. ${ }^{15}$ At T1 $(2013 ; \mathrm{N}=2338)$, $49 \%$ of the participants were 9th graders, $42 \%$ were 10th graders and $9 \%$ were 11 th graders. The participants were resurveyed $\sim 1$ year later at T2 (2014; $\mathrm{N}=2239$ ). For the longitudinal sample, the mean age was 14.8 years (SD 0.7) at $\mathrm{T} 1$ and was 15.8 years (SD 0.9 ) at T2. We tested for attrition effects in the longitudinal data and found some evidence of differential attrition (eg, more attrition among persons with higher rebelliousness or lower parental support), consistent with typical findings in longitudinal studies of adolescents. ${ }^{22}$ However, 
the effect sizes were small (for more detail see ref. 15). The sample was $57 \%$ female and $34 \%$ of the participants were of Asian-American background (Chinese, Japanese or Korean), 17\% were Caucasian, 25\% were Filipino-American, 17\% were Native Hawaiian or other Pacific Islander, and 7\% were of other race/ethnicity. Regarding family structure, $15 \%$ of participants lived with a single parent, 9\% were in a stepparent family (one or both parents were stepparents), 66\% lived with two biological parents and 10\% were in an extended family structure (two parents plus two or more relatives in the household). The mean for father's education on a 1-6 scale with anchor points grade school and postcollege was $4.3(\mathrm{SD}=1.1)$, a level just above high school graduate. (For a complete table of descriptive statistics, see online supplementary table S1.)

The sampling frame was all students in the 9th and 10th grades with adequate English language ability. The research was approved by the Institutional Review Boards of the University of Hawaii and the Hawaii State Department of Education. Signed parental consent and signed student assent were required at each assessment. The response rates were $70 \%$ at $\mathrm{T} 1$ and $67 \%$ at T2. The paper survey took $40 \mathrm{~min}$ and was administered by trained research staff in school classrooms. Students were instructed that data were confidential and they should not write their name on the survey. Participants were assigned an arbitrary numerical code to de-identify surveys while linking participants across data collection points. The majority of the nonparticipation was due to parents not returning the consent form (71\% of missing cases at both waves).

\section{Measures}

Demographics

Demographic variables included gender and age (written in years), family structure ('What adults do you live with right now?' with 9 response alternatives), parental education ('What is the highest level of education your father/mother has completed?' with 6 fixed responses from grade school to postcollege) and ethnicity (14 options including Chinese, Japanese, Korean, Native Hawaiian, Filipino and Caucasian). Students who checked more than one ethnicity were asked 'If you had to choose only one, what would you say?', and this item was used to index primary perceived ethnicity.

\section{E-cigarette and cigarette measures}

The item on e-cigarette use asked: 'Which of the following is most true for you about smoking electronic cigarettes (e-cigarettes, Volcanos)? (Check One)'. A 0-6 scale had response points 'I have never smoked an e-cigarette in my life', 'I have smoked e-cigarettes 1-2 times', 'I have smoked e-cigarettes 3-4 times', 'I usually smoke a few e-cigarettes a year', 'I usually smoke a few e-cigarettes a month', 'I usually smoke a few ecigarettes each week' and 'I usually smoke e-cigarettes every day'. The item on cigarette use had the stem, 'Which of the following is most true for you about smoking cigarettes? (Check One)'. This item also had a 0-6 response scale ('I have never smoked cigarettes in my life' to 'I usually smoke cigarettes every day'). T1 never-smokers who reported any smoking at T2 were considered to have initiated smoking.

\section{Propensity to smoke}

Three variables were assessed because they were known predictors of adolescent smoking ${ }^{19-21}$ and two were covariates in previous research. ${ }^{15}$ Items for parental support and rebelliousness were introduced with the stem, 'Here are some things that people may say about themselves. Read each one and circle a number (from 1 to 5 ) to show what is true for you'. Responses were on five-point Likert scales ('not at all true for me' to 'very true for me'). Parental support was a seven-item scale (T1 $\alpha=0.94$ ) assessing the perceived availability of emotional and instrumental support from parents (eg, When I feel bad about something, my parent will listen). Rebelliousness was a five-item scale (T1 $\alpha=0.84$ ) indexing the extent to which the youth liked to do things he/she was not supposed to (eg, I like to break the rules). The three items in the willingness measure were introduced with the stem: 'Suppose you were with a group of friends and there were some cigarettes you could have if you wanted. How willing would you be to: take one puff/smoke a whole cigarette/take some cigarettes to try later'. Responses were on fivepoint scales with response points not at all willing; a little willing; somewhat willing and very willing. The three items were combined with equal weight in a total score for willingness to smoke, which had $\alpha=0.91$.

\section{Analysis methods}

A preliminary analysis tested the role of rebelliousness, parental support and willingness for predicting smoking onset; categorical procedures were used to stratify the sample on a given risk variable (eg, rebelliousness) and determine the rate of smoking onset for low-risk and high-risk groups. To index smoking propensity, we created a weighted composite score ${ }^{23-25}$ by running a multilevel logistic regression analysis using the SAS V.9.4 SURVEYLOGISTIC procedure. Adjusting for clustering within schools, the procedure found the best fitting weighted combination of T1 rebelliousness (tercile), T1 parental support (tercile) and T1 willingness to smoke (tercile) predicting onset of smoking at T2 (ever smoked vs never smoked) among persons who had never smoked cigarettes at T1. For the analysis of differential susceptibility, assessing the interaction between ecigarette use and smoking propensity for predicting smoking onset, the e-cigarette variable and the propensity score were both converted to 0-6 scales for comparability of scaling. Using the SAS V.9.4 SURVEYLOGISTIC procedure for persons who had never smoked cigarettes at T1 and with smoking status at T2 as the criterion, we ran a multilevel logistic regression analysis. Level 1 variables were the covariates (gender, ethnicity and parental education), T1 e-cigarette use, T1 smoking propensity and their cross-product; school was a level 2 variable. Gender was coded as a binary variable, ethnicity was coded with four binary variables (Caucasian, Filipino, Native Hawaii and other ethnicity with Asian-American as the reference group) and father's education was a six-point scale. Onset was defined as ever smoked versus never smoked because previous research has shown that even minimal use of cigarettes significantly increases risk for regular smoking. ${ }^{26-28}$ We used a complete-case model with cases who had smoking data at $\mathrm{T} 1$ and $\mathrm{T} 2(\mathrm{~N}=1136)$ because a previous study showed similar results for completecase and full-information analyses. ${ }^{15}$ (Results were similar for a full-information analysis.) For T1 missing values, we computed multiple imputations employing the SAS V.9.4 MI procedure with 20 imputations based on the Markov Chain Monte Carlo method. ${ }^{29} 30$

\section{RESULTS}

Prevalence of ever-use at T1 indicated that $18 \%$ of the sample had used e-cigarettes only, 3\% had used cigarettes only, $13 \%$ of the sample had used both cigarettes and e-cigarettes, and $66 \%$ had never used either tobacco product. The present analysis is based on the subsample of participants who had never smoked cigarettes at T1. Data indicated that 92 persons $(8 \%$ of the initial 
never-smokers) had initiated smoking at T2. Of these, $14 \%$ had smoked 3-4 times and 22\% had smoked more often than this.

For a univariate test of differential vulnerability, the willingness variable was cut into groups representing no willingness versus any willingness to smoke, consistent with usual procedures in this area. ${ }^{19}$ A stratified analysis (table 1) indicated that among the low-risk group, the onset rate was $4 \%$ for those who did not use e-cigarettes and was 19\% for those who had used e-cigarettes; in the high-risk group the onset rates were $14 \%$ and 24\%, respectively. There was a main effect for the e-cigarette index, such that persons who had used e-cigarettes were more likely to smoke, and a main effect for the propensity index, such that high-risk participants were more likely to start smoking. However, the effect of e-cigarette use for onset was stronger in the low-risk group, $\chi^{2}(1)=43.46, p<0.0001$, than in the high-risk group, $\chi^{2}(1)=2.52, p=0.11$. Thus, the effect of ecigarette use for smoking onset was greater among those participants who initially were at lower risk for smoking on this index.

A comparable analysis was performed for the two other risk indices, which were cut at approximately the 75th centile (of high rebelliousness or low parental support). For rebelliousness as the risk index, the onset rate among low-risk participants was $4 \%$ for non e-cigarette users and $16 \%$ for e-cigarette users; among high-risk participants, the onset rates were $14 \%$ and $30 \%$, respectively. The effect of e-cigarette use was stronger in the low-risk group, $\chi^{2}(1)=28.53, \mathrm{p}<0.0001$, than in the highrisk group, $\chi^{2}(1)=6.78, p=0.01$. For parental support as the risk index, the onset rate among low-risk participants was 5\% for non-e-cigarette users and 18\% for e-cigarette users; among high-risk participants, the onset rates were $9 \%$ and $25 \%$, respectively. The effect of e-cigarette use was stronger in the low-risk group, $\chi^{2}(1)=36.66, p<0.0001$, than in the high-risk group, $\chi^{2}(1)=6.88, p=0.01$. In each case, there was a main effect for e-cigarette use and a main effect for the propensity index, with the onset rate greater for participants in the highrisk group. However, for both indices, the effect of e-cigarette use for smoking onset was greater among those participants who were at lower risk for smoking.

\section{Multiple logistic regression analysis}

A multiple logistic regression analysis based on T1 neversmokers, with ever-smoking at T2 as the outcome (ie, smoking

Table 1 Counts and percentage for ever-smoking at $\mathrm{T} 2$ in relation to e-cigarette use at $\mathrm{T} 1$ stratified by $\mathrm{T} 1$ willingness to smoke, among never-smokers at $\mathrm{T} 1$

\begin{tabular}{|c|c|c|}
\hline & \multicolumn{2}{|c|}{$\begin{array}{l}\text { Willingness to } \\
\text { smoke at } \mathrm{T} 1\end{array}$} \\
\hline & No & Yes \\
\hline \multicolumn{3}{|l|}{ Never used e-cigs at T1 } \\
\hline Never smoked at T2 & 780 & 92 \\
\hline (\% non-smokers) & (96) & (86) \\
\hline Smoked at T2 & 35 & 15 \\
\hline (\% smokers) & (4) & (14) \\
\hline \multicolumn{3}{|l|}{ Used e-cigs at $\mathrm{T} 1$} \\
\hline Non-smoker at T2 & 127 & 41 \\
\hline (\% non-smokers) & (81) & (76) \\
\hline Smoker at T2 & 29 & 13 \\
\hline (\% smokers) & (19) & (24) \\
\hline
\end{tabular}

Table 2 Multivariable logistic regression of relationship between smoking onset by $\mathrm{T} 2$ and demographics, $\mathrm{T} 1$ e-cigarette use, $\mathrm{T} 1$ smoking propensity, and interaction between $\mathrm{T} 1$ e-cigarette use and smoking propensity

\begin{tabular}{lclrcrc}
\hline T1 predictor & Estimate & SE & LCL & UCL & t & p Value \\
\hline Gender (male) & 0.00 & 0.09 & -0.19 & 0.19 & 0.00 & 0.99 \\
Ethnicity, Caucasian & 1.53 & 0.24 & 1.06 & 1.99 & 6.46 & $<0.0001$ \\
Ethnicity, Filipino & 0.91 & 0.367 & 0.18 & 1.64 & 2.46 & 0.01 \\
Ethnicity, Native & 1.37 & 0.36 & 0.67 & 2.07 & 3.82 & $<0.0001$ \\
Hawaiian & & & & & & \\
Ethnicity, other & 1.23 & 0.33 & 0.59 & 1.87 & 3.76 & 0.0001 \\
Father's education & -0.08 & 0.27 & -0.61 & 0.45 & -0.31 & 0.44 \\
E-cigarette use & 0.80 & 0.18 & 0.45 & 1.15 & 4.46 & $<0.0001$ \\
Propensity to smoke & 0.39 & 0.13 & 0.12 & 0.65 & 2.89 & $<0.01$ \\
E-cigarette & -0.13 & 0.05 & -0.23 & -0.03 & 2.50 & 0.01 \\
usexpropensity & & & & & & \\
\hline
\end{tabular}

Analysis based on T1 never-smokers.

Analytic $\mathrm{n}=1136$.

LCL, lower confidence limit; UCL, upper confidence limit.

Table 3 Detailed analysis of vulnerability differentials: adjusted OR for smoking onset by $\mathrm{T} 2$ stratified by 10 th-90th centile on propensity to smoke

\begin{tabular}{llll}
\hline $\begin{array}{l}\text { Propensity } \\
\text { Centile }\end{array}$ & $\begin{array}{l}\text { Adjusted OR of smoking onset } \\
\text { for T1 e-cigarette ever-use }\end{array}$ & $\begin{array}{l}\text { 95\% confidence } \\
\text { interval }\end{array}$ & p Value \\
\hline 10th & 2.23 & 1.57 to 3.17 & $<0.0001$ \\
25th & 2.18 & 1.56 to 3.06 & $<0.0001$ \\
50th & 1.76 & 1.47 to 2.10 & $<0.0001$ \\
75th & 1.42 & 1.31 to 1.54 & $<0.0001$ \\
90th & 1.32 & 1.19 to 1.47 & $<0.0001$ \\
\hline
\end{tabular}

OR adjusted for gender, ethnicity and father's education.

onset), tested main effect terms for T1 e-cigarette use and T1 propensity to smoke; their cross-product; and indices for gender (dichotomous), ethnicity (four binary indices) and parental education. The results (table 2) indicated significant main effects for T1 e-cigarette use and T1 propensity to smoke, both positively related to smoking onset; the cross-product term was also significant $(p=0.01)$. The model-estimated ORs for e-cigarette use at six percentiles of propensity to smoke, presented in table 3 , indicated that the effect of e-cigarette for smoking onset decreased as propensity increased. Graphing of model-estimated likelihood of smoking onset by level of e-cigarette use for cases at the 25th, 50th and 75th centiles on propensity to smoke (figure 1) showed the effect of having used e-cigarettes at T1 for smoking onset was greater among participants with lower propensity to smoke, with this effect diminishing at higher levels of e-cigarette use.

Other significant predictors of smoking onset were the four ethnicity indices. Participants from Caucasian, Filipino, Native Hawaiian and other ethnic backgrounds were more likely to begin smoking, compared with Asian-Americans. With control for e-cigarette use and propensity to smoke, gender and parental education were not significant predictors of onset in the model.

\section{DISCUSSION}

The goal of this research was to determine how e-cigarette use is related to onset of cigarette smoking for persons who were 


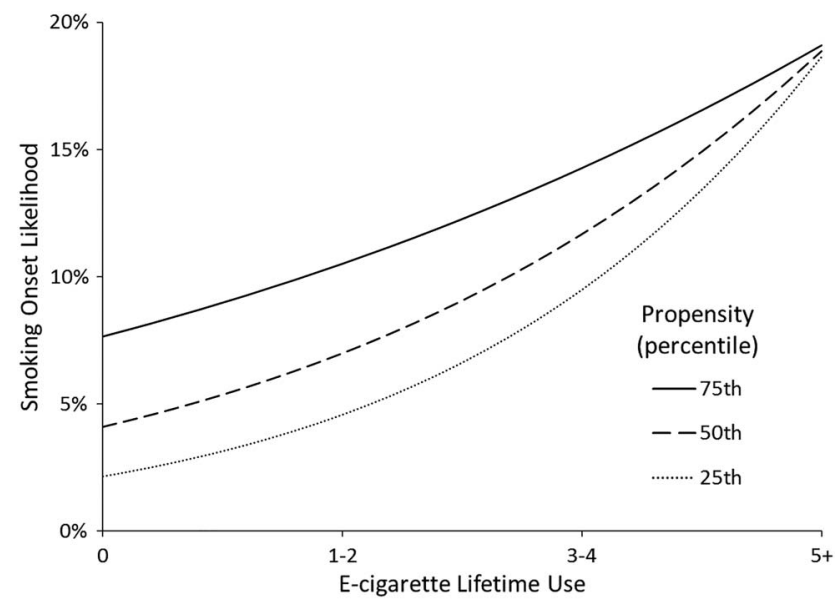

Figure 1 T1 e-cigarette use and estimated likelihood of T2 smoking onset, for quartiles of T1 smoking propensity score.

initially at lower versus higher risk for smoking. We obtained data on e-cigarette use and cigarette smoking from a sample of adolescents followed longitudinally with a 1-year interval and computed a score for propensity to smoke based on three variables that are recognised predictors of adolescent smoking. We tested whether there was a differential effect for each of the three components of the propensity index and then tested for an interaction of e-cigarette use and a smoking propensity score in a multivariable model with demographic controls. Results indicated that e-cigarette use had a greater effect for onset among those adolescents who initially had lower propensity to smoke.

The results bear on several questions about the public health significance of e-cigarette use in adolescence. It has been suggested that adolescent e-cigarette use is simply confounded with high-risk status and probably does not contribute to onset of smoking, ${ }^{17}$ but there has not been much empirical evidence about this proposition. The present study adds longitudinal data to this question, showing that the effect of e-cigarette use for smoking onset is greater among lower risk adolescents and that this finding was consistent across three different indicators of risk status. This finding is consistent with a recent report from a California sample, which also showed a greater effect of ecigarettes among lower risk adolescents. ${ }^{31}$ In view of these results, the concept that e-cigarette use only relates to smoking onset because of confounding with risk status is not supported. The finding is also noteworthy because several studies have shown that a substantial proportion of adolescents use e-cigarettes but do not smoke combustible cigarettes, hence are susceptible to transition to smoking. ${ }^{51-33}$ In addition, previous cross-sectional studies have suggested that e-cigarettes are recruiting lower risk adolescents to smoking, ${ }^{11} 12$ and this formulation is indeed consistent with the present longitudinal data.

The question of why lower risk adolescents would be attracted to e-cigarette use has few precedents in the literature but some factors can be suggested. Studies of reasons for ecigarette use indicate that curiosity, fashionability and social popularity are salient motives for use, ${ }^{34} 35$ and these are likely to be prominent motives among lower risk adolescents. The availability of attractive flavourings and the perception of e-cigarettes as healthier than cigarettes ${ }^{36} 37$ would also tend to encourage experimentation among youth who are less influenced by a desire to be risk-taking, rebellious and unconventional, the psychosocial profile that characterises teen cigarette smokers. ${ }^{5}{ }^{12}$ Studies suggest that concerns about addiction are not prominent among adolescents in general and only emerge as salient dimensions at later ages; ${ }^{38} 39$ in fact, a significant proportion of teen users report they did not know whether there was nicotine in the last e-cigarette they used. ${ }^{4}$ However, once lower risk users learn to inhale and start affiliating with higher risk teens who already have many risk factors, they may find themselves on a slippery slope, being exposed to conditions that produce increased vulnerability for transition to cigarette smoking.

The question of how e-cigarette use promotes smoking onset has not been completely clarified at this time. It has been suggested that favourable sensory experiences from e-cigarettes can produce more positive expectancies about tobacco cigarettes. ${ }^{10}$ Nicotine may be influential for some adolescents, as persons who experience mild withdrawal symptoms after e-cigarette use begin to look for a bigger 'kick' and turn to tobacco cigarettes as a way of providing this. ${ }^{14}$ Social-cognitive factors may also play a role if adolescents try e-cigarettes in groups of substance-using peers and acquire a smoker identity along with attitudes more tolerant of other substances. ${ }^{40-42}$ Further research is needed to test specific theoretical formulations about the role of e-cigarettes in smoking onset, examining multiple dimensions of predictors.

Some aspects of this study represent possible limitations. The measure of e-cigarette use did not provide detailed data on the type of product used or the context of use. ${ }^{43}$ At the time of the initial survey, most e-cigarettes marketed were cig-a-likes but a greater range of products are now marketed including tanks and e-hookahs. Further research should specifically assess what type of product is used. Also, there are different approaches for assessing susceptibility to smoking. ${ }^{44-46}$ In the present study, we indexed propensity to smoke with three different indicators and results were consistent across measures, but other approaches should be tested and compared. We did not assess level of nicotine dependence and the follow-up interval of 1 year was relatively short. However, we did find significant differential effects of e-cigarette use for low-risk and high-risk youth.

We think the findings have several implications for health education and smoking prevention. Since there is evidence that e-cigarettes may attract lower risk youth to vaping, educational programmes can be directed at the general adolescent population. Following successful models for cigarette smoking prevention, ${ }^{19} \quad 20 \quad 47$ programmes could address social-cognitive variables such as expectancies about physical effects and

\section{What this paper adds}

E-cigarette use has been shown to be associated with onset of cigarette smoking among adolescents, but it is not clear whether this might just mean that adolescents who were susceptible to smoking are more likely to use both substances.

- We tested this proposition with an empirically derived score for propensity to smoke cigarettes and found that the effect of e-cigarettes for smoking onset was stronger among participants who initially were at lower risk for smoking.

- The findings demonstrate that e-cigarette use is not just a marker for high-risk adolescents and show that e-cigarettes are a risk factor for smoking onset. This finding should be considered for policy formulation. 
perceptions of users ${ }^{19} 20$ as well as social aspects of use, explaining how perceived prevalence of use and affiliation with particular peer groups may affect attitudes and behaviour. ${ }^{40-42}$ Restrictions on access have recently come into place under the Food and Drug Administration (FDA) deeming regulations, but continuing attention is needed to norms about e-cigarette use and the cost-benefit breakdown of relative health benefits versus gateway effects. ${ }^{7} 36$ Finally, research has shown that marketing and media effects are significant influences on adolescent behaviour, ${ }^{21} 46$ so education about media literacy and lobbying for regulation of e-cigarette marketing to adolescents has a sound public health rationale.

Acknowledgements The authors thank the Superintendent of the Hawaii Department of Education and the Principals of the schools for their support, the participating parents and students for their cooperation, and Rebecca Knight for her able assistance with supervising the data collection.

Contributors TAW designed the parent study, performed the initial data analysis, wrote the first draft of the manuscript and coordinated the submission of the final manuscript. JDS assisted with the design of the parent study and conceptualisation of the data analysis and reviewed drafts of the manuscript critically for important intellectual content. FXG assisted with the design of the parent study and conceptualisation of the data analysis and reviewed drafts of the manuscript critically for important intellectual content. IP assisted with conceptualisation and performance of the data analysis and reviewed drafts of the manuscript critically for appropriateness and completeness of the statistical analyses. RS assisted with conceptualisation of the manuscript and reviewed drafts of the manuscript critically for important intellectual content.

Funding This research was supported by grants R01 CA153154 and P30 CA071789-16S2 from the National Cancer Institute.

Disclaimer The content is solely the responsibility of the authors and does not necessarily reflect the views of the National Institutes of Health.

Competing interests None declared.

Ethics approval The study was approved by the Institutional Review Boards for University of Hawaii and Hawaii Department of Education.

Provenance and peer review Not commissioned; externally peer reviewed.

Data sharing statement Data will be made available to qualified researchers when the study is completed. Data will be posted on a website and requests to use the data will be reviewed by a committee of three co-investigators.

\section{REFERENCES}

1 Arrazola RA, Singh T, Corey CG, et al. Tobacco use among middle and high school students-United States, 2011-2014. MMWR Morb Mortal Wkly Rep 2015;64:381-5.

2 Dutra LM, Glantz SA. High international electronic cigarette use among never smoker adolescents. J Adolesc Health 2014;55:595-7.

3 Dutra LM, Glantz SA. Electronic cigarettes and conventional cigarette use among U. S. adolescents. JAMA Pediatr 2014;168:610-17.

4 Krishnan-Sarin S, Morean ME, Camenga DR, et al. E-cigarette use among high school and middle school adolescents in Connecticut. Nicotine Tob Res 2015;17:810-18.

5 Wills TA, Knight R, Williams RJ, et al. Risk factors for exclusive e-cigarette use and dual e-cigarette use and tobacco use in adolescents. Pediatrics 2015;135: e43-51.

6 Fairchild AL, Bayer R, Colgrove J. The renormalization of smoking? E-cigarettes and the tobacco "endgame". N Engl J Med 2014:370:293-5.

7 Grana R, Benowitz N, Glantz SA. E-cigarettes: a scientific review. Circulation 2014:129:1972-86

8 Bunnell RE, Agaku IT, Arrazola RA, et al. Intentions to smoke cigarettes among never-smoking US middle and high school electronic cigarette users: National Youth Tobacco Survey, 2011-2013. Nicotine Tob Res 2015;17:228-35.

9 Coleman BN, Apelberg BJ, Ambrose BK, et al. Association between electronic cigarette use and openness to cigarette smoking among US young adults. Nicotine Tob Res 2015;17:212-18.

10 Wills TA, Sargent JD, Knight $R$, et al. E-cigarette use and willingness to smoke: a sample of adolescent non-smokers. Tob Control 2016;25:e52-9.

11 Hanewinkel R, Isensee B. Risk factors for e-cigarette, conventional cigarette, and dual use in German adolescents: a cohort study. Prev Med 2015:74:59-62.

12 Leventhal AM, Strong DR, Sussman S, et al. Psychiatric comorbidity in adolescent electronic and conventional cigarette use. J Psychiatr Res 2016;73:71-8.
13 Leventhal AM, Strong DR, Kirkpatrick MG, et al. Association of electronic cigarette use with initiation of combustible tobacco product smoking in early adolescence. JAMA 2015;314:700-7.

14 Primack BA, Soneji S, Stoolmiller M, et al. Progression to traditional cigarette smoking after electronic cigarette use among US adolescents and young adults. JAMA Pediatr 2015;169:1018-23.

15 Wills TA, Knight R, Sargent JD, et al. Longitudinal study of e-cigarette use and onset of cigarette smoking among high school students in Hawaii. Tob Control Published Online First: 25 Jan 2016. doi:10.1136/tobaccocontrol-2015-052705

16 Unger JB, Soto DW, Leventhal A. E-cigarette use and subsequent cigarette and marijuana use in Hispanic young adults. Drug Alcohol Depend Published Online First: 25 Apr 2016. doi:10.1016/j.drugalcdep.2016.04.027

17 Bauld L. Expert reaction to study of e-cigarette use and cigarette smoking in children. http://www.sciencemediacentre.org/

expert-reaction-to-study-of-e-cigarette-use-and-cigarette-smoking-in-children Posted 25 January 2016.

18 Sullum J. Why that study of teenagers in Hawaii does not show vaping causes smoking. Forbes, 2016.

19 Gibbons FX, Stock ML, Gerrard M, et al. The prototype-willingness model. In: Conner M, Norman P, eds. Predicting and changing health behaviour: research with social cognition models. 3rd edn. Berkshire, UK: Open University Press, 2015:189-224.

20 Williams RJ, Knight RA, Wills TA. Why children smoke in 2015 and prospects for stopping them: a review of current literature. Curr Cardiov Risk Rep 2015;9:45.

21 Wills TA, Sargent JD, Stoolmiller M, et al. Movie smoking exposure and smoking onset: a longitudinal study of mediation processes in a representative sample of U.S. adolescents. Psychol Addict Behav 2008;22:269-77.

22 Wills TA, Walker C, Resko JA. Longitudinal studies of drug use and abuse. In: Sloboda Z, ed. Epidemiology of drug abuse. New York: Springer, 2005:177-92.

23 Rosenbaum PR, Rubin DB. The central role of the propensity score in observational studies for causal effects. Biometrika 1983;70:41-55.

24 Rosenbaum PR, Rubin DB. Reducing bias in observational studies using subclassification on the propensity score. J Am Stat Assoc 1984;79:516-24.

25 McCaffrey DF, Ridgeway G, Morral AR. Propensity score estimation with boosted regression for evaluating causal effects in observational studies. Psychol Methods 2004;9:403-25

26 Chassin L, Presson CC, Sherman SJ, et al. The natural history of cigarette smoking: predicting young-adult smoking outcomes from adolescent smoking patterns. Health Psychol 1990;9:701-16

27 Dierker L, Mermelstein R. Early emerging nicotine-dependence symptoms: a signal of propensity for chronic smoking behavior in adolescents. J Pediatr 2010;156:818-22.

28 Sargent JD, Primack B, Soneji S. Longitudinal studies of e-cigarette use and its relation to subsequent cigarette use in older adolescents and young adults. In: Wills TA, Chair, Consequences of e-cigarette use in adolescents and young adults. Symposium presented at the NIH Conference on Tobacco Regulatory Science; Bethesda, MD, 2016.

29 Schafer JL, Graham JW. Missing data: our view of the state of the art. Psychol Meth 2002; 7:147-77.

30 Shafer JL. Multiple imputation: a primer. Stat Methods Med Res 1999:8:3-15.

31 Barrington-Trimis JL, Urman R, Berhane K, et al. E-cigarettes and future cigarette use. Pediatrics 2016;138:e20160379.

32 Barrington-Trimis JL, Berhane K, Unger JB, et al. Psychosocial factors associated with adolescent electronic cigarette and cigarette use. Pediatrics 2015;136:308-17.

33 Bostean G, Trinidad DR, McCarthy WJ. E-cigarette use among never-smoking California students. Am J Public Health 2015;105:2423-5.

34 Kong G, Morean ME, Cavallo DA, et al. Reasons for electronic cigarette experimentation and discontinuation among adolescents and young adults. Nicotine Tob Res 2015;17:847-54.

35 Pepper JK, Ribisl KM, Emery SL, et al. Reasons for starting and stopping electronic cigarette use. Int J Environ Res Public Health 2014;11:10345-61.

36 Pepper JK, Brewer NT. Electronic nicotine delivery system (electronic cigarette) awareness, use, reactions and beliefs: a systematic review. Tob Control 2014:23:375-84.

37 Johnston LD, O'Malley PM, Miech RA, et al. Monitoring the future national survey results on drug use, 1975-2015: overview, key findings on adolescent drug use. Ann Arbor, MI: Institute for Social Research, the University of Michigan, 2016.

38 Pokhrel P, Herzog TA, Muranaka N, et al. Young adult e-cigarette users' reasons for liking and not liking e-cigarettes: a qualitative study. Psychol Health 2015;30:1450-69.

39 Pokhrel $\mathrm{P}$, Little M, Fagan $\mathrm{P}$, et al. Electronic cigarette use outcome expectancies among college students. Addict Behav 2014;39:1062-5.

40 Hoffman BR, Sussman S, Unger J, et al. Peer influences on adolescent cigarette smoking: a theoretical review of the literature. Subst Use Misuse 2006;41:103-55.

41 Sussman S, Pokhrel P, Ashmore RD, et al. Adolescent peer group identification and characteristics: a review of the literature. Addict Behav 2007;32:1602-27.

42 Wills TA, Sussman S, McGurk M. Identity development and substance use in adolescence. In: Brown S, Zucker R, eds. Oxford handbook of adolescent substance abuse. New York: Oxford University Press, 2015:1-32.

43 Pokhrel P, Herzog TA, Muranaka N, et al. Contexts of cigarette and e-cigarette use among dual users: a qualitative study. BMC Public Health 2015;15:859. 
44 Pierce JP, Choi WS, Gilpin EA, et al. Validation of susceptibility as a predictor of which adolescents take up smoking in the United States. Health Psychol 1996;15:355-61.

45 Strong DR, Hartman SJ, Nodora J, et al. Predictive validity of the expanded susceptibility to smoke index. Nicotine Tob Res 2015;17:862-9.
46 McClure AC, Stoolmiller M, Tanski SE, et al. Alcohol marketing receptivity, marketing-specific cognitions, and underage binge drinking. Alcohol Clin Experiment Res 2013;37:E404-13.

47 Sussman S, Ames SL. Drug abuse: concepts, prevention, and cessation. New York: Cambridge University Press, 2008. 